\title{
Educação em tempos de transição
}

\section{Education in times of transition}

\section{lêda Aleluia' 1 Ana Verônica Mascarenhas² Sandra Lúcia Brasil ${ }^{3}$ (1)}

\footnotetext{
'Autora para correspondência. Escola Bahiana de Medicina e Saúde Pública (Salvador). Bahia, Brasil. iedaleluia@bahiana.edu.br 2,3Escola Bahiana de Medicina e Saúde Pública (Salvador). Bahia, Brasil. avmbatista@bahiana.edu.br, sandrabrasil@bahiana.edu.br
}

Come gather 'round people, wherever you roam And admit that the waters around you have grown The Times They Are A-Changin', Bob Dylan ${ }^{1}$

Há tempos estamos em processo de transição no ensino na saúde. Temos nos perguntado como fazer melhor para alcançar os estudantes, esses nativos digitais que nos forçam a olhar de forma diferente para nossas metodologias de ensino e aprendizagem, que nos questionam sobre maneiras diferentes de apresentar nossas aulas, alunos que "fogem" das salas de aula e nos deixam perplexos com a capacidade que têm em buscar caminhos de chegar ao conhecimento.

Esses mesmos alunos que, em vários momentos se rebelam contra as metodologias ativas, que demandam aulas teóricas presenciais, em um velho modelo que tanto temos lutado para modificar. Onde está a raiz desse paradoxo aparente? Em nossa própria condição humana, de rebeldia, de questionamento, de movimento.

E, nesse momento de pandemia pelo COVID-19, vírus mutante, onde temos que estabelecer o distanciamento social, manter salas de aula fecha- das, como juntar esses fios? Como correr com a mudança, e chegarmos inteiros em um lugar de equilíbrio? São tantas questões, tantas incertezas, tantas lacunas a serem preenchidas...e em tempo recorde. Não podemos mais nos sentar em uma zona de conforto, e fazer mudanças passo a passo, em velocidade de caramujo. Nossa geração de transição, deve mudar rápido, deve incorporar tecnologias rapidamente, precisa criar novas sinapses, novas formas de se relacionar com o novo. Terminologias como: vídeo aulas, plataformas $x-y-z$, links, salas de aula virtuais, chats e fóruns de discussão síncronos e assíncronos, provas online...tudo o que deixávamos para depois, pois o "agora" era presencial e o toque, o parar no corredor para tirar dúvidas era o habitual. Tudo isso mudou em poucas semanas, a evolução que levaria meses, até anos, deve se dar em semanas...e nós estamos nos adaptando. Como seres adaptáveis ao extremo, mostramos nossa capacidade de sobrevivência.

O que fica para pensarmos não é sobre nossa capacidade de adaptação, é sobre mantermos nossa reflexão sobre o processo de adaptação, é sobre mantermos nossa humanidade, nossa ética 
e nosso compromisso para com o outro em toda essa mudança. É sobre mantermos a proximidade na distância, a transparência em tempos sombrios, o olhar sobre o outro e sobre nós mesmos.

O mundo mudou. A educação não fica de fora dessa mudança, e a educação em saúde também não. Então que mudemos, que naveguemos em" mares nunca dantes navegados" com a incerteza nos acompanhando; pois é com essa incerteza, com esse sentimento de fluidez, de mudança constante, que poderemos ver, e nos lançar, nas várias possibilidades de novos caminhos. Que as mudanças nos façam meIhores, que nos façam crescer, que aumentem nossa curiosidade, nossa solidariedade, nossa criatividade. Que nos façam ver a importância da construção coletiva do conhecimento. Que não fiquemos trancados em certezas vãs, em fórmulas rígidas, em zonas de conforto que dão aparente segurança e força, já que a vida se baseia na impermanência. Aprender a lidar com a incerteza é aprender a lidar com a vida.

A medicina, e todo o conjunto das profissões de saúde, tem uma estrutura de base rígida, necessária para se manter através dos tempos, levando uma imagem de confiança para a sociedade, pois tem uma fundamentação científica na observação e na experiência. Essa base é necessária, porém as profissões de saúde são formadas por pessoas que cuidam de pessoas, e como tal, mutáveis, adaptáveis, em constante evolução. E é nesse sentido que a educação para formar os profissionais de saúde também evolui, muda, se adapta aos novos desafios, e busca despertar esse sentimento tanto em quem ensina e aprende quanto em quem aprende, para posteriormente ensinar.

É nos desafios que o mundo nos apresenta que formamos e somos formados; é na relação consigo mesmo e com o outro (indivíduo e comunidade) que evoluímos. O momento atual nos obriga a aprofundar o nosso aprendizado, construindo uma nova forma de relação com o outro, consigo mesmo, com o conhecimento. Estamos em transição, em mutação, em local de incerteza...que possamos aprender e crescer. Que possamos utilizar esse momento de crise para transformar a educação.

Nós aceitamos o desafio de nos aventuramos corajosamente nesse novo mundo que se desenha, com o saber que acumulamos ao longo do tempo, e com a determinação de aprender o que não sabemos ainda. Com o olhar cheio de sensibilidade para o novo, para nós mesmos e para o outro, pois como diria Rubens Alves: "Sem a Educação das Sensibilidades, todas as habilidades são tolas e sem sentido."

\section{Referências}

\footnotetext{
1. Dylan B. The Times They Are A-Changin' [Internet]. Disponível em: https://www.letras.mus.br/bob-dylan/11920/traducao.html

2. Aleluia IMB. Sobre educação médica e sensibilidades: revisitando Rubem Alves!. Rev Inter Educ Saúde. 2018;2(1):124125. doi: 10.17267/2594-7907ijhe.v2i1.2091
} 